\begin{tabular}{|l|l|l||}
\hline \multicolumn{2}{|c|}{ PublisherInfo } \\
\hline \hline PublisherName & $:$ & BioMed Central \\
\hline \hline PublisherLocation & $:$ & London \\
\hline \hline PublisherImprintName & $:$ & BioMed Central \\
\hline \hline
\end{tabular}

\title{
Safer (but not better) imaging
}

\begin{tabular}{|l|l|l||}
\hline \multicolumn{2}{|c|}{ ArticleInfo } \\
\hline \hline ArticleID & $:$ & 1602 \\
\hline \hline ArticleDOI & $:$ & $10.1186 /$ rr-2001-68502 \\
\hline \hline ArticleCitationID & $:$ & 68502 \\
\hline \hline ArticleSequenceNumber & $:$ & 13 \\
\hline \hline ArticleCategory & $:$ & Paper Report \\
\hline \hline ArticleFirstPage & $:$ & 1 \\
\hline \hline ArticleLastPage & $:$ & 3 \\
\hline \hline & & RegistrationDate : 2001-9-14 \\
ArticleHistory & $:$ & Received \\
& & OnlineDate \\
\hline \hline ArticleCopyright & $:$ & Biomed Central Ltd2001-17 \\
\hline \hline ArticleGrants & $:$ & \\
\hline \hline ArticleContext & $:$ & 129312211 \\
\hline \hline
\end{tabular}


Stephen Ellis, Aff1

Corresponding Affiliation: Aff1

Aff1 The Royal Brompton Hospital, London, UK

\section{Keywords}

Cancer, CT, screening

\section{Context}

Screening for lung cancer, based on plain chest X-ray (CXR), failed to demonstrate a reduction in mortality (see Additional information [1,2]). The potential of low-dose computed tomography (CT), which is more sensitive and specific than CXR, to identify early surgically curable lung cancers, has renewed interest in lung cancer screening. Very low dose CT scanning has reduced the radiation dose of a screening chest $\mathrm{CT}$ to about 10 times that of $\mathrm{CXR}$. Further reduction in radiation dose will enhance the suitability of CT as a screening modality, but will the image quality be sufficient?

\section{Significant findings}

The authors found that the lowest-dose technique using their new filter was superior to CXR and as good as conventional CT in detecting nodules greater than $5 \mathrm{~mm}$. They conclude that further reduction in radiation dose of CT scanning for lung cancer screening is possible by using an appropriate filter.

\section{Comments}

This paper reflects a drive toward making CT scanning an acceptable modality for lung cancer screening. The authors have reduced the radiation dose from CT scanning by a further $50 \%$ compared to previous low dose $\mathrm{CT}$ techniques without, according to them, a significant reduction in image quality. The $5 \mathrm{~mm}$ cut-off for significant lesions is reasonable; nodules of less than $5 \mathrm{~mm}$ will be assigned to conventional follow-up in the proposed UK screening trial. Image quality at the apices is poor with lowdose techniques and lung cancer screening with $\mathrm{CT}$ scanning has yet to be shown to be effective. It is likely that screening trials, endeavouring to demonstrate the efficacy of CT scanning, are likely to adopt a protocol that is acceptable on dose criteria resulting in the minimum reduction in image quality. Even 
though lower dose techniques will be available, their efficacy in terms of screening will not have been evaluated.

\section{Methods}

Spiral CT, x-ray filtering

\section{Additional information}

1. Miller AB: Screening (lung cancer).

Chest 1986, 89:324S-326S.

2. Kubik A, Polak J: Lung cancer detection. Results of a randomized prospective study in Czechoslovakia.

Cancer 1986, 57:2427-2437.

\section{References}

1. Itoh S, Koyama S, Ikeda M, Ozaki M, Sawaki A, Iwano S, Ishigaki T: Further reduction of radiation dose in helical CT for lung cancer screening using small tube current and newly designed filter. J Thorac Imaging. 2001, 16: 81-88. 